Crespo, Natalia. "Personajes femeninos en Margarita (1875) de Josefina Pelliza de Sagasta. Symposium: A Quarterly Journal in Romance Literatures. Syracuse University. ISSN: 00397709 (en prensa).

\title{
Personajes femeninos en Margarita (1875) de Josefina Pelliza de Sagasta
}

\section{Natalia Crespo}

\section{(ILAR, FFyL, UBA-CONICET)}

En los últimos años han surgido varios estudios sobre la literatura argentina del siglo XIX que llevan adelante una labor de rescate y revaloración de novelas y novelitas escritas aproximadamente entre 1838 y 1880 , casi todas bastante desconocidas, nunca re-editadas y en peligro de desaparición. A partir de estos rescates se desmiente la creencia -arrastrada a lo largo de las diversas historias de la literatura argentina- de que la novelística decimonónica de este país ha tenido tan sólo dos etapas de esplendor: las novelas anteriores a Caseros (Amalia como texto canónico y fundacional) y las surgidas en la década de 1880 (bajo las estéticas del Naturalismo, el Realismo costumbrista y la fantasía científica principalmente). ${ }^{\mathrm{i}}$ Como es de suponer, dentro de estas tres décadas rescatadas (1850-1880), la literatura ha ido modificándose y tomando diversos rumbos. A partir de 1870 o, más específicamente, la etapa comprendida entre 1872 y 1879 es considerada por Molina como el "período de la revolución silenciosa", dado que durante estos años "la novela se diversifica en formas y temas" y "las variantes de lo fantástico, la cienciaficción y lo policial" conviven con otras formas que se mantienen más conservadoras, como la escritora que aquí nos ocupa, Josefina Pelliza de Sagasta, ${ }^{\text {ii }}$ quien "prolonga la novela sentimental y melodramática con Margarita (1875) y La chiriguana (1877)" (Molina, s/p). Por su parte, Graciela Batticuore registra los cambios en el sistema literario del período y los asocia al 
surgimiento de nuevos imaginarios sobre las mujeres: "[...] hacia fines del 70 y el 80 -cuando pululan ya los semanarios para mujeres y las escritoras no son una excepción- el auge del romanticismo y las problemáticas que le son inherentes ceden terreno o bien compiten por entonces con nuevas figuraciones de la mujer letrada que se cristalizan en la narrativa finisecular, en la cual se hace sentir la presencia de otras estéticas como el realismo y el naturalismo." Así, comienzan a surgir otros modos de representar a las mujeres, superando el modelo romántico y sentimental de la lectora romántica, pasiva, obediente y abocada al hogar: “aparece el imaginario amenazante de otra clase de mujeres que 'traicionan' el hogar y ponen en riesgo una de las instituciones clave de la república: el matrimonio.” (Batticuore 335)

La obra de Pelliza consta de tres novelas (Margarita, 1875; La Chiriguana, 1877; El César, 1882), del volumen de artículos Conferencias: el libro de las madres (Buenos Aires: Lavalle, 1885) y de los poemarios Lirios silvestres (1877), Canto inmortal (1885) y Pasionarias (1888). Sus artículos periodísticos aparecieron en publicaciones de la época tales como América poética, Parnaso argentino, Álbum poético argentino, La Alborada del Plata. Varios de sus poemas han sido incluidos en antologías del siglo XIX. Este artículo busca llenar cierto vacío bibliográfico al ofrecer una lectura crítica de Margarita (1875), la novela más importante de la escritora Josefina Pelliza de Sagasta (Entre Ríos, 1848 -Buenos Aires, 1888). Margarita ha recibido hasta hoy muy poca atención por parte de la crítica especializada (ver bibliografía), por el hecho básico y fundamental de su inaccesibilidad: hasta hace poco, era una obra totalmente desconocida. En 2013 descubrí en los anaqueles de la Biblioteca Nacional de la República Argentina uno de los dos últimos ejemplares existentes (el otro se halla en la Biblioteca de la Academia Argentina de Letras), que re-edité en 2016 con un estudio introductorio. 
A partir de considerar los cuatro personajes femeninos más importantes (Margarita, Teresa, Andrea e Inés), planteamos que en este texto conviven elementos de la novela romántica sentimental con rasgos del melodrama clásico (el argumento, el lenguaje y cierta postura crítica hacia la sociedad y hacia el matrimonio). Una oposición al matrimonio por parte de otra escritora latinoamericana contemporánea de Pelliza es la que hallamos en la cubana Gertrudis Gómez de Avellaneda. A través del análisis de sus cartas, Nuria Girona Fibla sugiere que mediante las anécdotas evocadas de la infancia, Gómez de Avellaneda logra constituirse como una joven que desestima matrimonios y no tiene inconvenientes en coquetear; es decir, en la construcción narrativa de su vida, la escritora cubana "luce su rareza y particularidad (...) debe separarse del resto (...) en su negación de la feminidad.” (Girona Fibla 138)

En Margarita pueden verse dos modelos contrapuestos de mujer: por un lado, la figura más tradicional de esposa y madre abnegada (representada por Andrea y Teresa, personajes tradicionalmente románticos, de la literatura sentimental, sistema estético residual para 1875) y, por otro, figuras femeninas de conducta y pensamiento más diversos: la protagonista, Margarita, e Inés, la prostituta. Margarita puede pensarse como la antesala de un personaje femenino moderno: aunque no posee profundidad psicológica, por sus desacuerdos con ciertos aspectos de la sociedad, por sus contradicciones y luchas internas, es un sujeto rico y ambivalente, al modo de las heroínas literarias del siglo XX. Por su parte Inés, aunque de menor importancia narrativa en la novela que la protagonista (e incluso menos importante en la trama que las dos figuras románticas por antonomasia, Andrea y Teresa) es clave como personaje canalizador de la denuncia de la marginalidad social y de un sistema de exclusiones. En este sentido, Margarita es también un testimonio de lo que planteaba Batticuore en su estudio de la mujer romántica: "la presencia amenazante de otra clase de mujeres que 'traicionan' el hogar y ponen en riesgo una de 
las instituciones clave de la república: el matrimonio." (335) Asimismo, esta curiosa novela de 1875 da cuenta del pasaje desde una praxis novelística prescriptiva - en donde la obra literaria quedaba subordinada a su misión educadora y moralizante, funcional al proyecto civilizador de la dirigencia- hacia una noción más moderna y secular de dicho género, pensado ahora como artefacto autónomo, regido por sus propias reglas intra-textuales. ${ }^{\text {iii }}$ Por supuesto, el advenimiento de una nueva figura de mujer (letrada, escritora por vocación aunque no aún con esta dedicación reconocida como "oficio") y el pasaje hacia una praxis literaria menos subsumida a la esfera social (aunque no aún autónoma) no son fenómenos separados. En este sentido, vale la pena recordar la reflexión que hay en la carta prólogo (de "Josefina" para "Florencia," a quien la autora dedica la obra): "una mujer, por mas que sea madre y esposa, tiene tiempo, si sus ideas y su corazon la inclinan á ello, para escribir y hacer versos."

\section{Margarita: un melodrama clásico con preocupaciones argentinas}

Según Peter Brooks, el melodrama es un modo narrativo surgido en el teatro del S.XVIII y popularizado por la novela europea decimonónica. Se trata de historias maniqueas, de gran intensidad emotiva, que llevan al lector a sentir comprensión, identificación y afecto por personajes en posición de víctimas, y odio y rechazo hacia los personajes considerados "villanos." Las víctimas que protagonizan el melodrama, "los buenos," suelen ser personajes de mujeres jóvenes, bellas y de alta moral. ${ }^{\mathrm{v}}$ Estas heroínas suelen estar sometidas a innumerables injusticias pertrechadas por un villano que irrumpe en la felicidad inicial. A esta irrupción en un primer estado de armonía entre los personajes, Brooks la denomina "el banquete violentado." (161) En el argumento melodramático típico, tras la lucha y la resistencia de los héroes ante los embates del Mal, finalmente triunfa el Bien. En este sentido, el melodrama ha sido pensado como "un elogio y una apología del sufrimiento pero también de la lucha contra la adversidad." 
(Brooks 14) En la representación del Mal (el cual suele ocupar la mayor parte del espacio narrativo), el melodrama configura sociedades crueles e injustas hacia seres débiles y nobles.

Los rasgos que suelen caracterizar al melodrama son: representaciones polarizadas del mundo (el Bien contra el Mal) y personajes estereotípicos; una conexión determinista entre la ética, la estética y la clase social (los pobres suelen ser bellos y buenos, mientras que los ricos tienden a la fealdad y a la vileza); una fuerte presencia de la religión o de las invocaciones a Dios (apelaciones recurrentes de parte de los sufrientes buenos); una temporalidad indeterminada; el claro predominio de los sentimientos por sobre la razón; una voz narrativa única que monopoliza el punto de vista; una gran intensidad afectiva; escenas de violencia, de catástrofes inesperadas y/o de alto erotismo. Subyace, por lo general, un sentido de destino trágico, una suerte de futurología o vaticinio que se desprende del relato de las desgracias pasadas, que contienen en sí mismas saberes ocultos. Se trata de historias de alto expresionismo, concluye Brooks, que apelan al corazón más que a la razón, y que buscan conmover, aunque también entretener y moralizar.

Ben Singer propone que, por lo general, "una de las cosas más llamativas del melodrama es que genera dos horizontes de deseo: las representaciones de la economía imperial y de la moral burguesa están acompañadas de momentos en que se cuestionan esos mismos valores e instituciones." (Singer 14; la traducción es mía) Esos dos horizontes representan dos temporalidades o modos de conciencia, uno que ha ocurrido efectivamente y otro que se plantea como horizonte ideal, a alcanzar." (Singer 14) Por el mundo conflictivo, agresivo e inseguro que representa, el melodrama ha sido pensado por muchos teóricos (Grimsted, Singer, Kaplan) como uno de los modos narrativos que mejor expresa la angustia que deviene de la secularización. También en torno a esta vivencia de angustia, Clayton Hamilton plantea que el melodrama da cauce ficcional al sentido de injusticia y arbitrariedad que vive el sujeto moderno: 
Much of our life -by far, the major share- is casual instead of causal [...] Nearly all the good or ill that happens to us is drifted to us, uncommanded, undeserved, upon the tides of chance. It is this immutable truth -the persistence of chance in the serious concerns of life and the inevitable influences of accident on character -the melodrama aims to represent [...] We derive a solid comfort from our certainty that the virtue of the heroine is inviolable. (Hamilton 313)

Las arbitrariedades del azar, la desprotección (secular, por otra parte) que genera la sensación de que el destino es inmanejable, quedan claramente expresadas en Margarita, como así también la inviolabilidad de la virtud de la heroína, su postrer triunfo por sobre los embates del villano. Veamos primero, brevemente, su línea argumental principal. La novela cuenta la vida de su protagonista homónima desde que tiene 17 años y vive con quien ella considera su padre, el viejo Saavedra (el villano, cuyo verdadero nombre es Luis Rizzio), hasta que Margarita cuenta aproximadamente con 24 años, y Saavedra muere. Durante esos años, innumerables acontecimientos desgraciados se suceden en la vida de la protagonista, Margarita: se enamora del joven Santillana, se embaraza, se despide de su novio (quien debe viajar de urgencia a Chile), se fuga de su casa paterna (pues descubre que Saavedra, a quien creía su padre, es en verdad su acosador), da a luz a un hijo, (el pequeño Edgardo, que será raptado por Saavedra), enloquece a raíz de este secuestro y es internada en un hospicio, se recupera y vive un tiempo en la casa de su amiga Teresa, se hace hermana de Caridad, conoce a sus verdaderos padres, luego logra reunirse con su amante y con su hijo. Finalmente, cuando la familia de "los buenos" está re-encontrada para siempre, el villano confiesa sus engaños y delitos, pide perdón, es absuelto por Margarita y muere. No es un dato menor el arrepentimiento final de Saavedra, el causante de todas las desgracias: muestra no sólo la capacidad de perdón de los buenos (Margarita y quienes la rodean, 
como dicta la generosité heroica, son dechados de virtud), sino también el movimiento de conversión del villano. La "virtud triunfante" es el asunto principal del melodrama (Brooks, $E l$ folletín 155): "la víctima salvando la vida del victimario, poniéndolo bajo la protección del sagrado emblema que representa el sufrimiento y la virtud." (Brooks, El folletín 154)

También se narra en esta novela, a través del recurso del manuscrito encontrado (el diario Andrea y una carta de Saavedra, papeles que aparecen recién en el capítulo XVII), la infancia de Margarita, su vida anterior al presente del relato, el orden que la llegada del villano ha roto, tema tan caro al melodrama clásico. Ambos datos inscriben a la novela, una vez más, en la modalidad melodramática: las cartas encontradas y el descubrimiento de un pasado idílico perdido por culpa de la villanía. Marlyse Meyer explica que en el melodrama, "el enredado sistema de engaños y pistas falsas hacen de la vieja fórmula del misterio del pasado aclarado por cartas, algo mucho más que un artificio para mantener el interés.” (250) Respecto de la nostalgia del pasado idealizado, propone Brooks que existe en el melodrama la noción del trauma original, aquel en el cual el Mal aparece por primera vez y deja a la virtud humillada y estupefacta. ${ }^{\text {vii }}$

Ahora bien, ¿en qué medida la teoría del melodrama, surgida a partir de un corpus europeo y norteamericano, puede resultar útil para pensar la novela de Pelliza? Habría que marcar, primero que nada, una serie de elementos de Margarita que dan cuenta de las preocupaciones y de la idiosincrasia de la clase social privilegiada y letrada a la cual pertenecía esta autora. El conflicto disparador de la trama, aquello que rompe el clima de locus amoenus inicial, es la inmigración indeseada, en concreto, la llegada al país del italiano Luis Rizzio (o Saavedra). Según podemos reconstruir a partir del diario de Andrea (el cual aparece recién promediando la novela), Luis Rizzio llega a la Argentina y, bajo el nombre falso de Saavedra, se hace amigo y se aloja en casa del argentino Augusto (el padre biológico de Margarita). Augusto vive en el campo, en la 
provincia de Buenos Aires, con su esposa, Andrea, y con su pequeña hija, también llamada Andrea (luego rebautizada por el villano Rizzio/Saavedra como "Margarita.") En ausencia del amigo, y en la propia casa de Augusto, Saavedra acosa a Andrea y amenaza con matarla si ella no accede a sus pretensiones sexuales. Ante la negativa de la mujer, el italiano rapta a la beba y se fuga a Buenos Aires. Allí se re-instala en una casona lujosa de las afueras de la ciudad. Cría a la niña haciéndole creer que él es su verdadero padre y rebautizándola "Margarita." Cuando Andrea/Margarita llega a la edad madura y se transforma en una hermosa joven (época en la que se inicia la novela), Saavedra desea poseerla sexualmente: esta es la primera escena del texto, (la cual es, a su vez, repetición de la que viviera el villano con Andrea madre años atrás.)

Se trata de un argumento a todas luces melodramático: una heroína bella e inocente se ve forzada a luchar contra el Mal para recuperar su verdadera identidad violentada o, en palabras de Marlyse Meyer, "los temas de la heroína cuya vida está amenazada, del rapto de niños, del protector desconocido y misterioso; los peligros constantes, los villanos." (247) Durante los intensos años de la vida de Margarita que constituyen el presente de la narración (y que se corresponden con su edad de 17 años), la joven descubre su verdadera identidad (su nombre real es Andrea, como su madre) e ingresa en la vida adulta. Ninguna de estas dos cosas -el conocimiento de su verdadero origen y el ingreso en la adultez- son procesos fáciles, dado que el acoso y la sed de venganza del villano la acechan en todo momento.

¿En qué se distancia Margarita del modelo europeo de melodrama? Además de la mencionada cuestión italo-fóbica, se trata de una novela ambientada en Buenos Aires. Constatamos, pues, aquella reflexión de Curia en torno a las novelas argentinas de mediados del siglo XIX: "Más allá de las diferencias temático-estructurales, se advierte en casi todas ellas una constante: la preocupación de los novelistas por argentinizar las novelas, es decir, por ambientar 
las historias en algún momento de nuestra historia y en algún lugar del país, y por destacar los valores morales que persisten en nuestra sociedad, diferenciándola de las europeas." (25) viii

\section{Estereotipos de la literatura sentimental}

En su estudio de la dinámica evolutiva de la cultura, Raymond Williams propone que cada período de la historia está habitado por elementos interdependientes identificables como residuales, dominantes y emergentes. Lo residual "ha sido formado efectivamente en el pasado, pero todavía se halla en actividad dentro del proceso cultural; no sólo -y a menudo ni eso- como un elemento del pasado, sino como un efectivo elemento del presente (...) que puede presentar una relación alternativa e incluso de oposición con respecto a la cultura dominante.” (144) ${ }^{\mathrm{ix}}$ Margarita posee una serie de elementos que la sitúan, como propone Molina, dentro de las formas novelísticas de la década de 1870 que se mantienen más conservadoras (Molina, s/p). Uno de estos elementos es la configuración de los personajes de Teresa y Andrea como típicas heroínas de la literatura sentimental. Ambas pueden pensarse como elementos residuales del Romanticismo, el cual para 1875 va dejando lugar al Realismo y al Naturalismo.

Una de las características de las heroínas de la literatura sentimental es que aparecen representadas idílicamente. Esto ocurre con Teresa, la mejor amiga de Margarita y su única confidente de toda aquella información que se presenta al principio de la novela como "prohibida" (o cuya declaración sería escandalosa): el amor de Margarita hacia Plácido (sospechado en un principio de ser el asesino del hermano de la joven), o sus dudas respecto de la autenticidad de su padre, el viejo Santillana. Teresa, como digna depositaria de estos secretos primero, y de las injusticias del villano, luego, es una joven de una belleza angelical, dócil, buena, "enteramente espiritual" (Pelliza 74). De ella se dice que "(e)ra blanca, esbelta y elegante; su rostro puro y ovál tenía toda la celestial hermosura que sin duda poséen los ángeles de Dios; 
[...] Aquella mujer era lo ideal de lo bello, el ensueño rosado de un poeta" (Pelliza 10). Como contrapunto, Margarita posee una belleza pasional, propia de la esfera terrenal. Leemos:

Margarita, con su naturaleza ardiente y ávida de impresiones, á los quince años forjó su ideal y amó una ilusión que no tardó en realizarse. -Plácido fue el amor de su alma, el único amor de su vida, pero la noble jóven llevaba impreso en su frente el sello negro de una horrible fatalidad y fue la víctima, la mártir sublime del ódio implacable de un malvado. La estrella que debía alumbrar el camino de Teresa era, por el contrario, benigna y clara como sus propias pasiones: á su corazon, virgen todavía, no le llegaba la hora, ella debía amar, pero amar sin deseo, sin ardor, con un amor purísimo, enteramente espiritual, con un afecto noble y divino, como sin duda lo sienten los ángeles. (Pelliza 74)

Espiritual y asexuada, desde el punto de vista de la estructura melodramática, Teresa es un personaje esencial a la trama: además de ser quien ayuda a Margarita en los momentos más trágicos, es la principal testigo de la virtud de violentada y, por tanto, infaltable en la estructura melodramática. Brooks llama "abogados de la virtud" a todos aquellos personajes que, por conocer la historia de la protagonista desde su origen, "despliegan todas las armas para obtener la victoria de la verdad por sobre la apariencia, y para explicar el sentido profundo de los signos enigmáticos y engañosos." (164) Será Teresa quien, cuando la protagonista enloquece, le explique a los doctores la causa de esta locura. Durante la internación de Margarita en el hospicio (el momento sin duda más trágico de la obra), las atenciones que le dispensa Teresa son tantas y tan buenas que Fernando, el médico que atiende a "la loca," (Pelliza 97) concluye: "Creed, Teresa, que con vuestra angélica ternura haréis más que cuanto la medicina puede hacer.” (99) Andrea, madre biológica de Margarita, a diferencia de Teresa, ni siquiera circula por la ciudad. Este personaje es, en cuanto a modelos de conducta femenina, el más conservador de la 
novela. Feliz en su encierro doméstico, laboriosa, devota de su marido y de sus hijos, no tiene otro deseo que el de servir a su familia: “¡Ah! que placer indescriptible es el de zurcir y componer la ropa del hombre querido, del esposo tierno y enamorado," (146) leemos en su diario íntimo, el mismo que nos revela el verdadero origen de la protagonista. Más adelante, tras la sugerencia de Augusto, su marido, de mudarse a la capital, Andrea escribe: "Yo no puedo dejar mi casa, mis flores, mi alegre jardincito puesto por mí misma [...] yo no quiero salir de mi retiro donde solo he respirado felicidad.” (146). Tras narrar la fascinación que le provoca la rutina diaria de las tareas del hogar, esta esposa modélica concluye: "Mi deseo es amar y ser amada; formar la familia y cuidar del hogar; mis aspiraciones agradar a mi esposo, hacer dulce y alegre su vida personificando nuestras dos almas en una sola." (147) El diario de Andrea ofrece una nueva perspectiva de la dicotomía sarmientina: el campo no es el desierto bárbaro (como opina su marido) sino un espacio rural idealizado, el locus amoenus que se perderá con la aparición del italiano: la campiña, el jardín trabajado, la naturaleza domesticada. La mujer argentina es la mejor pobladora para "este desierto." (146) La barbarie reside, entonces, en dos amenazas para esta armonía: Rizzio, que llega para intentar violarla, y la ciudad, antro en donde "solo se aprende el fingimiento y la mentira, donde se vizia la pureza del sentimiento y hasta las santas afecciones de la esposa suelen ser una farza infame." (147)

\section{La marginalidad de la prostituta Inés}

En el capítulo XIX aparece un nuevo personaje: Inés, prostituta y madre soltera, que deviene por necesidad amante de Saavedra (173). Está descripta como una mujer "de pequeña estatura, aunque de andar elegante y gracioso", con ojos "negros y ardientes" que "despedían rayos de inquietud." (175) Por desesperación económica, Inés finge ternura y amor hacia Saavedra, se convierte en su querida. Si bien la voz narrativa la presenta como un ser corrompido 
y marginal, el texto se encarga de aclarar que Inés es moralmente menos baja que el villano. Posee la suficiente nobleza como para horrorizarse ante la maldad del italiano: "miró con repugnancia a aquel miserable asesino, y el único sentimiento, quizá, noble que habia en su corazon, se desperto de repente ante la inmensa desgracia de Santillana.” (174) Así, en el escalafón moral del melodrama, los corrompidos por necesidad (personajes, por otro lado, identificados por Brooks como recurrentes en esta modalidad narrativa) son seres más respetables y sensibles a la recuperación que los villanos, condenados a abogar en favor del Mal.

Tras descubrir que el italiano planea asesinar al pequeño Edgardo, el hijo indefenso de Margarita y su amante Santillana, y conmovida ante el sufrimiento del padre del niño, la prostituta Inés decide “convertirse” al Bien. Esta conversión consiste en la decisión de alertar a Santillana acerca de los macabros planes de Saavedra. Es expresada en voz alta, casi declamada, como ocurre con muchos pensamientos de los personajes melodramáticos: "No importa, se dijo, lo engañaré por mas que esto sea un tormento y quien sabe, tal véz pueda ser util á ese pobre padre.” (174) Es así como Inés va hasta el hotel en donde se encuentra el desgarrado Santillana y le confiesa que su pequeño hijo Edgardo vive, ha sido secuestrado por Saavedra, y pronto podría ser asesinado. Ante este gesto de nobleza de la prostituta, Santillana agradece y retribuye: "Yo sabré recompensaros, le dijo, desde hoy en adelante tu hijo tendrá un padre en mí, y vos volveréis a ser honrada y tendreis un hermano en Plácido Santillana.” (178) Así, como el personaje de Jacobo Retamares (otro ser marginal del texto) Inés "se salva” de una vida "deshonrosa" gracias a la protección de Santillana, ganada tras haber procedido virtuosamente. La conversión de Inés, su abandono de la prostitución, asombra a Santillana y se narra a partir del imaginario del catolicismo. Tras escuchar la recompensa de Santillana, Inés dice: 
Gracias señor, esclamó dando mil besos a la mano de Plácido [...]-Yo no sé señor qué timbre mágico tiene vuestra voz; parece que hubiera salido de repente de la vida de vicio y lodo en que he vivido hasta aquí y que vuestro acento semejante a la voz de Cristo al convertir á Magdalena hubiera purificado mi alma y la voz del deber llamado á mi extraviada conciencia. (178)

Ante esta declaración de agradecimiento, Santillana, puesto aquí en el lugar de Cristo, nos ratifica la concepción cristiana del ser humano que predomina como sustrato ineludible de toda la novela: Pobre jóven, se dijo, así son la mayor parte de estos seres prostituidos. Casi todos á pesar de la corrupcion de su cuerpo y sus costumbres conservan innata la pureza de sus sentimientos y cuando su conciencia llega a despertarse son susceptibles de todo lo noble y generoso. (178-79)

Los "falsos villanos," como Inés y Jacobo, que poseen en el fondo "un alma sensible," son rápidamente perdonados por los poderosos virtuosos. Así, a diferencia de otras novelas en donde una conducta prostituida hubiera acarreado una condena social por parte de la voz narrativa, en Pelliza (y esto se verá también en los personajes de La Chiriguana), la concepción cristiana prevalece por sobre el juicio moral: Inés no sólo es perdonada sino que pasa a ser una pieza clave en la relevación de la verdadera identidad de la protagonista. La sociedad porteña que se presenta en Margarita es injusta, cruel, poblada de seres engañosos (villanos), seres marginales (envilecidos por necesidad) y de pocas almas buenas. No sólo de Inés y de Jacobo se apiada el texto: también Juan, el negro al que alude la voz narrativa en el capítulo XXII: “¡Pobre Juan! pobre negro! fiel y noble, martir sublime de un afecto sin retribucion, -tú éras un pária en la vida, nadie te amaba, á nadie estabas ligado -has muerto ignorado y ni siquiera han comprendido tu generoso sacrificio.” (196) A través de estos personajes marginales, la novela denuncia que la 
mala distribución de la riqueza obliga a algunos seres de alma noble a ejercer actividades inmorales para sobrevivir. En este sentido, realiza una operación propia del melodrama (Singer X): llena un vacío representacional: da visibilidad a seres y situaciones ignorados.

\section{La elocuencia crítica de Margarita}

Según Brooks, la mudez como símbolo de la indefensión de la inocencia, de su incapacidad física para protestar ante las injusticias, suele caracterizar a las protagonistas del melodrama clásico. ${ }^{\mathrm{x}}$ Pero lejos de dicha mudez de la heroína clásica, Margarita nunca se queda callada. En este sentido, la elocuencia de la protagonista, su valentía para esgrimir respuestas ante las injusticias del villano o para expresar su desacuerdo ante la sociedad, marcan una distancia más con el modelo europeo. Por ejemplo, tras descubrir que Saavedra no sólo no es su verdadero padre sino que además la desea sexualmente, la joven exclama: “-_Que consienta tu amor! gritó Margarita, pálida de indignación. -¡Miserable! te detesto, me horrorizas como un leproso y á través del ódio que me inspiras, te miro mas detestable que un mónstruo infernal!” (62)

Ante el insistente acoso del villano, la joven amenaza con denunciarlo a la justicia:

-¿Qué dijiste, miserable? dijo-¿quién te dio derecho para insultarme así? di, miserable, ¿quién, cuando con solo delatarte a la justicia te arrancaria esa máscara hipócrita con que ocultas la podredumbre de tu alma envilecida y amasada con el crímen, esa falsa careta de virtud que jamás conociste y por la que el mundo te respeta sin imaginar que le engañas con la mas repugnante de las farsas? ¿Quién te ha autorizado, prosiguió la joven creciendo en indignacion -quién te ha dado derecho para hablarme así, cuando con solo hablar una palabra puedes vivir el resto de tus dias en el calabozo? (63)

Además de la habilidad para defenderse, otra muestra del coraje de Margarita es su negativa a casarse con Santillana antes de que el joven parta hacia Chile. Con la excusa de que primero debe 
conocer su verdadera identidad, la protagonista posterga el contrato civil. A raíz de dicha postergación, se esbozan una serie de ideas contrarias al matrimonio, que siguen la línea (persistente en toda la novela y típica del melodrama) de oponer la honestidad de los sentimientos a las falsedades de la sociedad. Se ofrece pues -innovadoramente para su época- una defensa de la unión por amor, presentada como contraria al matrimonio, visto como una unión por compromiso. De este modo, Margarita le plantea a Santillana, ya estando embarazada: "tú profesas las mismas creencias y comprendes el matrimonio como lo comprendo yo; haremos el contrato social para el mundo, y el contrato del alma lo haremos nosotros mismos." (42)

Otro aspecto innovador, muy relacionado con la mirada crítica hacia el matrimonio, es la aceptación de las relaciones sexuales pre-maritales. Veamos el momento previo a la unión de los amantes y cómo el texto justifica la "entrega" de Margarita:

La inocente vírgen se estremeció, inclinó la frente cubierta de rubor sobre el pecho generoso de Santillana y una impresion nueva y dulcísima recorrió las fibras de su cuerpo; la luz de la luna dio de lleno sobre aquel grupo encantador, y Plácido, reteniendo a su amada en sus brazos, selló aquella frente pura con un casto beso. Margarita nada dijo-ni un solo reproche salió de sus lábios, ni la más mínima resistencia notó Plácido en su cuerpo ¿y para qué? No era de Santillana su alma entera, no le amaba con toda la fuerza de lealtad y de pasion que cabia en su corazon? Entónces, ¿a qué un melindre de mal gusto? ¿a qué una resistencia ridícula cuando se ama como ella amaba? (21)

Narrativamente, se independiza la moral de Margarita (una cualidad de su espíritu, por tanto permanente), de su castidad (un estado provisorio). Pero además de lo incuestionable de la moral de la joven (para cuya narración se apela al imaginario religioso), hay aquí otra serie semántica, propia de la construcción de la virtud de la heroína que hace el melodrama: los "dictados del 
corazón," es decir, sentires que les vienen dados a los personajes "buenos" a modo de mandatos internos, certezas que no se explican lógicamente pero que ellos acatan sin cuestionamiento: "No era de Santillana su alma entera, no le amaba con toda la fuerza de lealtad y de pasion que cabia en su corazon?" Así, a la hora de narrar cómo Margarita le declara su amor a Santillana, la escritura fusiona dos líneas semánticas recurrentes en la obra: la cristiandad y el placer erótico:

Sí, Plácido, sí, te amo, dijo Margarita levantando al cielo su frente iluminada por un rayo de purísima fé.... [...] te he amado desde el instante en que te vieron mis ojos; desde entónces te he amado con un amor puro y sublime como el martirio; ha sido un secreto tremendo que ha abrasado mi corazon y que ya rebelde por su propia fuerza, era un crimen sofocarlo. ¡Te amo, ahora mas que nunca y de hoy en adelante mi único placer será pensar en ti, mi única ambicion que tú me ames! (20).

La retórica cristiana se mezcla con los dictados del corazón: "hay una voz secreta que me dice que te ame sin remordimientos, y yo, olvidando todas las preocupaciones de la conciencia, te amaré como se ama a Dios y te miraré como el ángel bueno de mi vida.” $(24)^{\mathrm{xi}}$ Es con el aval de esta "voz secreta", que los jóvenes viven el encuentro erótico pre-marital:

Cuando el reloj del suntuoso comedor de Saavedra dejaba oir la última vibracion de las doce de la noche, un hombre saltaba las tápias, y Margarita, siempre enamorada, siempre bella, esperaba á su amante sentada bajo un árbol en lo mas oculto del jardín. [...] cuando la luz crepuscular del nuevo dia teñia de ténue sonrosado el firmamento, los amantes se despedian tiernamente, renovando sus juramentos de constancia eterna. (27)

Este noviazgo se desarrolla a espaldas de Saavedra, dura un breve lapso pero es vivido intensamente: "Plácido y Margarita, olvidados del mundo, veían solo á través de su dicha y llegaron á persuadirse de que el universo estaba encerrado en su amor, y ambos, viviendo solo el 
uno para el otro, se lanzaron en brazos de la felicidad presente sin recordar el porvenir" (Pelliza 27). La experiencia amorosa transforma para siempre a la heroína y dicha transformación es narrada, una vez más, entrecruzando el paradigma cristiano con el erótico. Así, arribamos a una nueva transgresión de la protagonista (a tono con su oposición al matrimonio): el momento en que le cuenta a su amiga y confidente, Teresa, sus amores con Santillana:

...cuando él con su ternura digna, pero no menos ardiente, en sus inefables desvaríos inició mi virgen corazon en todos los deleites del amor, pensé con dolor que jamás sería su esposa y al mismo tiempo una felicidad inmensa inundó mi corazon; ¡qué importa! dije, no soy su esposa, seré su querida, y así sacrificándolo todo por el hombre amado, todo, con una espontaneidad sublime, seré mil veces mas dichosa, y no vacilé, Teresa mia. (38)

Tras insinuar la ventaja de ser querida vs. ser esposa, el texto retorna a la yuxtaposición de catolicismo y amor erótico: "El rostro de Margarita, animado por un santo entusiasmo, tenía en aquel momento un tinte de fé y de pasion inconcebible, era la personificacion de la nobleza y abnegacion mas hermosa que pueda existir en el corazon de la mujer." (38) No solamente la novela rodea de ennoblecimiento moral a la joven (soltera y embarazada), a partir de utilizar recurrentemente una retórica católica, sino que, ante ella, su amiga (todavía virgen) es presentada como aniñada y moralmente inferior: "Teresa la contemplaba con mudo respeto; Margarita era tan superior en su modo de sentir, que la pobre niña, cándida y tímida, se sentía ante ella humillada, como la modesta violeta ante la reina de las flores.” (39)

Las expresiones de altura moral de Margarita son recurrentes: "En la bella frente de la joven estaba impreso el sello de una voluntad suprema. Su acento noblemente altivo hacia traslucir el orgulloso timbre de una raza pura. Margarita, luchando con dos pasiones poderosas, el amor y el deber, no podía confundírsele con la vulgaridad de una plebeya." (42) Esta insistencia en la alta 
moral de la protagonista es, además de un rasgo melodramático, la condición de posibilidad para que se enuncien ciertas ideas contrarias al matrimonio. Es la misma Margarita quien le cuestiona a su amado, Plácido, su deseo de que contraigan matrimonio:

No comprendo tu empeño en una union que ya nuestras almas la han efectuado, un sacerdote unirá nuestras manos, nos dirá unas frases sin sentido para nuestros corazones ya eternamente unidos en la tierra y mas tarde en el cielo--y luego, muy satisfecho se retirará creyendo que con aquella estúpida forma social, que con aquella irrisoria imposicion de los hombres, no de Dios, que ha unido nuestras almas por medio de dos palabras. (Pelliza 47; la cursiva es mía).

Estas ideas de Margarita son compartidas por su amante: los jóvenes entienden que el matrimonio es una institución "imprescindible para obtener el aprecio social y sostener el buen nombre que llevarán más tarde nuestros hijos.” (47) Así, tras un breve intercambio de ideas, ambos coinciden en el rechazo "con repugnancia" del matrimonio (47):

Tu alma no comprende que pueda imponerse á otra voluntad, á otra alma, un deber u obligacion que coarta las puras y naturales espansiones de los sentimientos espontaneos, mil veces mas hermosos y duraderos que los que nos son obligatorios, haciendo siempre una víctima y un verdugo, ó cuando menos una esclava sumisa, y un amo que aunque sea tierno y condescendiente, al fin es amo. (48)

Si bien Margarita le asegura a su amado "soy feliz con que tú seas mi amo," la ideología textual queda clara en la respuesta que Santillana le da a la protagonista: "Sí, pero eres esclava por tu libre voluntad.” (Pelliza 48) Así, a través del recurso del diálogo, Margarita (acaso Pelliza) puede expresar -y logra el acuerdo de su amado-su oposición a la institución del matrimonio. ${ }^{\text {xii }}$ Lo que se menciona antes en la novela como "delicadeza" (la joven no quiere casarse hasta saber su 
verdadero apellido) deviene, en la confrontación (aparente) de ideas, un alegato contra el sometimiento que conlleva el estar casada.

Pero el carácter innovador de Margarita en tanto mujer ejemplar no se limita a sus elocuentes defensas ni a sus opiniones contra el matrimonio ni a sus amoríos previos al casamiento. Sabemos que dentro de un proyecto de nación liberal, la mujer es la encargada de sostener la estructura familiar: ser buena esposa y madre abnegada (el prólogo lo ratifica). Pues hay en esta novela ciertas situaciones de vida de la protagonista que desmienten o se desvían drásticamente de este modelo. ¿Cómo es que Margarita vive en una pensión que ella misma ha elegido y alquilado, haciendo trabajos de costura y criando sola al pequeño Edgardo, quien "como todos los hijos del amor" es "el retrato perfecto del padre" (57) y se halla -aquí está la transgresión mayor de la narradora- "feliz en su pobreza?" (68) Si bien narrativamente esta situación queda justificada a partir de la compleja trama de enredos (Margarita tuvo que escapar de su casa por haber sido acosada por Saavedra, está temporalmente sola porque su amado tuvo que viajar de urgencia a Chile), otro modelo posible de vida queda sugerido.

Cabe aquí recuperar la propuesta de Julio Ramos: la literatura es el lugar para diseñar moralidades edificantes. Ahora bien, ¿se trata indefectiblemente de argumentos y personajes ejemplares o, más bien, podemos pensar (como propone Singer) que algo del texto melodramático siempre escapa a la moral dominante? Además de cristalizar el sueño del proyecto liberal de nación (que entendía el matrimonio como organización social mínima imprescindible para el desarrollo de una economía capitalista), la novela sirve, en cierta medida, como espacio en donde proyectar el ideal de un deseo (en este caso, un deseo de género, tal vez calificable de proto-feminista si recordamos la subordinación jurídica de la mujer en el matrimonio, según explica Barrancos,) y no ya el de la nación. xiii $^{\text {na }}$ 
La retórica cristiana paradojalmente sirve aquí como modo de suspender el juicio moral y, por ende, suavizar el ingreso en el texto del amor erótico premarital. Si bien Margarita, como todo personaje melodramático, no tiene profundidad psicológica, está llena de dilemas internos (en más de una ocasión la vemos "luchando con dos pasiones poderosas, el amor y el deber." (42)

\section{Conclusiones}

Hemos ofrecido un análisis de los cuatro personajes femeninos principales -Teresa, Andrea, Inés y Margarita- de la primera novela de la escritora entrerriana Josefina Pelliza de Sagasta. A través de Teresa, íntima amiga de la protagonista y testigo de la virtud violentada, se perpetúa el estereotipo de la heroína romántica, casi un elemento residual en el sistema literario de 1875. Pero lo sentimental retorna con más fuerza en la figura de Andrea, en cuyo diario se expresan las ideas más conservadoras de la novela: el mejor destino para una mujer (acaso el único) es ser esposa y madre, dedicar el día a las labores domésticas en una casa en medio del campo en espera del marido (profesional, urbano, integrado a la sociedad del trabajo). Por su parte, Inés, aunque de los cuatro personajes el menos presente, cumple un rol fundamental en la trama: gracias a su conversión de prostituta a mujer "de bien," se esclarece la confusión en torno al pequeño Edgardo, hijo de Santillana y Margarita, raptado por el villano. Además, el personaje de Inés, típicamente melodramático, también es significativo porque a través de él se representa una sociedad cruel e injusta, con seres marginados por necesidad económica. En cuanto a la protagonista, hemos visto cómo a través de sus alocuciones directas se expresan en la novela unas cuantas ideas contrarias al matrimonio, por demás innovadoras para la época, sobre todo si provienen de una mujer. Asimismo, a través de los avatares en la vida de Margarita y de sus actitudes frente a ellos (ambos, avatares y actitudes, respondiendo a la matriz narrativa melodramática) se sugieren $-\mathrm{O}$, al menos, se ficcionalizan como posibles- ciertos modelos de 
conducta femenina nada en línea con la moral republicana y las preceptivas de la naciente sociedad liberal para las niñas pudientes. Planteamos que estas tensiones o desvíos respecto de la norma dominante están narrados desde una retórica religiosa: así, el amor erótico premarital se presenta como un dictado del corazón y, a la vez, casi como un designio divino.

En síntesis, consideramos que Margarita contiene -sin llegar a ser una novela rupturistano pocas contradicciones e ideas de avanzada para su época. Ni tan modélica como las novelitas del '50, ni tan polisémica como la literatura del siglo $\mathrm{XX}$, puede pensarse como un texto no exento de cierta crítica hacia la sociedad y, ante todo, más plural respecto de modelos de vida femenina que sus predecesoras. En este sentido, la matriz narrativa del melodrama -con las variaciones argentinas del modelo europeo- se torna una herramienta clave: es por su virtud violentada y por su defensa de las injusticias perpetradas por el villano que la heroína puede permitirse libertades y ofrecer un caso "ficcional" de conducta femenina menos "ejemplarizante." Una joven que tiene relaciones pre-maritales pero, al mismo tiempo, es una honrosa cristiana; una madre soltera que no ha perdido por ello el respeto social, la hija que se atreve a cortar lazos con su padre y no depender económicamente de ningún hombre, ni siquiera la prostituta es enjuiciada moralmente por la voz narrativa sino, por el contrario, es presentada como un alma noble y desesperada. En este sentido, el melodrama es la condición de posibilidad, el molde narrativo que le permitió a Pelliza validar -ficcionalizándolas- otras conductas femeninas posibles. 
${ }^{\text {i }}$ Para una síntesis del desarrollo de la novelística del siglo XIX y sus limitaciones o exclusiones, ver Molina.

ii Es poco lo que se sabe hoy de Josefina Pelliza. En el Nuevo diccionario biográfico argentino (1750-1930), Vicente Cutolo refiere que la autora "nació en una trashumante carreta en Concordia (Entre Ríos) el 4 de abril de 1848” y murió en Buenos Aires “el 10 de agosto de 1888, a los cuarenta años de edad." En coincidencia con Néstor Auzá y Lily Sosa de Newton, Cutolo comenta que la escritora era hija del coronel José María Pelliza y de Doña Virginia Pueyrredón. Dora Barrancos, en su artículo sobre el cruel matrimonio de Amalia Pelliza, hermana de Josefina, con el Dr. Durand, escribe: "Los Pelliza Pueyrredón en realidad estaban en bancarrota. Quien más se destacaba en la familia era su hermana Josefina, poetisa y novelista, al parecer muy bella, casada con Sagasta, y que murió joven, asistida por su amiga Juana Gorriti.” (116)

iii En este sentido, cabe recordar lo que explica Julio Ramos respecto del lugar de la literatura tras las luchas de Independencia: la escritura devino el lugar "ficticio, acaso, donde se proyectaban los modelos de comportamiento, las normas necesarias para la invención de la ciudadanía, los límites y las fronteras simbólicas, el mapa imaginario, en fin, de los estados en vías de consolidación. (8)" De este modo, "la escritura proveía un modelo, un depósito de formas, para la organización de las nuevas naciones; su relativa formalidad era uno de los paradigmas privilegiados del sueño modernizador, que proyectaba el sometimiento de la "barbarie" al orden de los discursos, de la ciudadanía, del mercado, de los Estados modernos.” (Ramos 13) iv Tanto en esta cita de los textos de Pelliza como en las siguientes, he respetado la ortografía original. 
${ }^{\vee}$ Sobre la recurrencia del melodrama a escoger protagonistas femeninas, ver el capítulo II del libro de Peter Brooks.

${ }^{\text {vi }}$ Karen Kaplan estudia el melodrama del siglo XX, y sobre todo aquel de la pantalla grande, desde una perspectiva feminista: cómo están representadas las mujeres en las películas de Hollywood. Sin embargo, algunas de sus afirmaciones son válidas para pensar un corpus melodramático del siglo XIX. Según Kaplan, el melodrama suele narrar historias de mujeres que sufren pero triunfan; se trata de relatos que buscan infundir coraje y perseverancia ante la adversidad, y que presentan una sociedad injusta y villana de un modo un tanto paranoico, con el fin de advertir a las lectoras sobre los peligros que acechan en el mundo masculino y adulto.

vii “El logro del mal en la obra se vincula con él [el momento del trauma original], ya que ofrece un horror presente explicable por completo no sólo en términos de un horror pasado, fiel en este sentido a la estructura del trauma patogenético de Freud. Subsumida en el horror, la virtud debe someterse a una experiencia de lo intolerable." (Brooks, El folletín 169)

viii En la otra novela de Pelliza, La Chiriguana (1877), lo melodramático aparece más “argentinizado" aún: la ficción está ambientada en la región del Chaco, a orillas del Río Bermejo, sus personajes son todos indios chiriguanos (excepto Dalma, un cacique inca), y la voz narrativa plantea preocupaciones locales políticamente más incómodas quizás que la cuestión italiana (que generaba parejo rechazo en las clases privilegiadas): las condenas a pena de muerte ejecutadas en las plazas de Buenos Aires, la idiosincrasia indígena según la autora, la incorporación a la sociedad blanca y la cristianización de los indios del norte argentino.

${ }^{\text {ix }}$ Aclara Williams que esta categoría de lo residual "es muy notable en el caso de las versiones de la tradición literaria, pasando a través de las versiones selectivas del carácter de la literatura hasta 
las definiciones conectoras sobre lo que la literatura es hoy y sobre lo que debería ser." (145) Por "emergente" Williams entiende "los nuevos significados y valores, nuevas prácticas, nuevas relaciones y tipos de relaciones que se crean continuamente" (146).

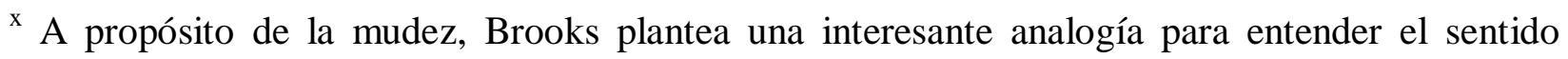
subyacente del melodrama, de la tragedia y de la comedia (que, en su concepción, son las tres formas narrativas principales): "Es una tentación pensar que los diferentes tipos de dramas tienen correspondencia con una incapacidad de los sentidos: para la tragedia, la ceguera, ya que la tragedia trata de introspección e iluminación; para la comedia, la sordera, ya que la comedia tiene que ver con problemas de comunicación, malentendidos y sus consecuencias; y para los melodramas, la mudez, ya que el melodrama apunta sobre todo a la expresión.” (Brooks, $E l$ folletín 204)

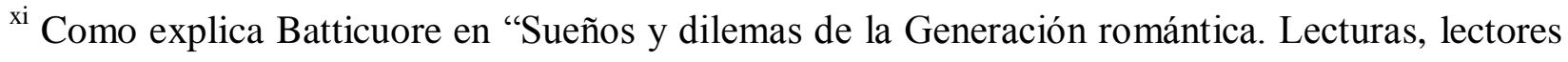
y lectoras entre 1830 y 1850 ", hay que tener en cuenta las múltiples capas de censura que median entre autoras y lectoras (amén de la censura interna de cada una de ellas): los padres eran muchas veces quienes seleccionaban, desde su autoridad paterna y desde el poder económico, todas las lecturas de las jóvenes.

${ }^{\text {xii }}$ Molina y Curia han analizado la cuestión, recurrente en la literatura de la primera mitad del siglo XIX, del matrimonio por amor vs el matrimonio por conveniencia. Carlos Mayo también da cuenta de este debate y explica que, a raíz de los matrimonios arreglados por conveniencia económica, era frecuente entre los jóvenes casarse a muy temprana edad y a espaldas de la familia. Sin embargo, aquí Pelliza va un paso más adelante: no se trata de oponerse tan sólo al matrimonio arreglado por conveniencia económica sino al matrimonio como institución social 
que somete a la mujer. Para una historia del matrimonio en la época colonial en el Río de la Plata, ver Cicerchia.

xiii Es notoria aquí la coincidencia entre la historia del encarcelamiento doméstico sufrido por la hermana de Josefina, Amalia Pelliza, en manos de su despótico marido, el Dr. Durand (historia que es explicada en detalle por Barrancos), y el rechazo de Josefina hacia el matrimonio. ¿Estaría la escritora pensando en su hermana a la hora de ficcionalizar su rechazo hacia esta institución social?

\section{Obras citadas}

Auzá, Néstor Tomás. La literatura periodística porteña del siglo XIX: De Caseros a la Organización Nacional. Buenos Aires: Confluencia, 1999.

Barrancos, Dora. "Inferioridad jurídica y encierro doméstico.” Historia de las Mujeres en la Argentina. T.I. Colonia y Siglo XIX. Dir. Fernanda Gil Lozano, Valeria Silvina Pita y María Gabriela Ini. Buenos Aires: Taurus, 2000. 111-129.

Batticuore, Graciela. La mujer romántica: Lectoras, autoras y escritores en la Argentina; 1830 1870. Buenos Aires: Edhasa, 2005.

Brooks, Peter. The Melodramatic Imagination: Balzac, Henry James, Melodrama, and the Mode of Excess. New York: Columbia University Press, 1985.

---. "La estética del asombro." El folletín y sus destinos. Migraciones y trasposiciones en los imaginarios culturales argentinos del siglo XX. Ed. María Inés Laboranti. Trad. Estefanía 
Viglione. Santa Fe: Universidad Nacional del Litoral, 2012. 153-202.

Cicerchia, Ricardo. "Historia de las prácticas, discursos y representaciones familiares. El espectáculo del disenso en la ciudad secular.” Revista Iberoamericana, 70.206 (enero-marzo 2004): 37-52.

Crespo, Natalia. "Margarita: un melodrama del siglo XIX.” Margarita. Novela original de Josefina Pelliza de Sagasta. Buenos Aires: Teseo, 2106.

---. “Una mirada sobre los indios del Río Bermejo." La Chiriguana. Novela original de Josefina Pelliza de Sagasta. Buenos Aires: Teseo, 2106.

Curia, Beatriz. "Introducción.” María de Montiel. Novela contemporánea (1861). Rosas de Rivera. Mercedes (M. Sasor). Ed., estudio y notas de Beatriz Curia. T.I. Buenos Aires: Teseo, 2010. 11-49.

Cutolo, Vicente Osvaldo. Nuevo diccionario biográfico argentino (1750-1930). Buenos Aires: Elche, 1985.

Girona Fibla, Nuria. “Amos y esclavos: ¿quién habla en Sab de Gertrudis Gómez de Avellaneda?" Cuadernos de Literatura 13.33 (enero-junio 2013): 121-140.

González-Stephan, Beatriz. "La in-validez del cuerpo de la letrada: la metáfora patológica." Cuadernos de Literatura 1233 (enero-julio 2013): 164-186.

Grimsted, David. "Melodrama as Echo of the Historically Voiceless." Anonymous Americans: Explorations in Nineteenth-Century Social History. Ed. Tamara Hareven. New Jersey: Prentice Hall, 1971. 80-98.

Hamilton, Clayton. "Melodrama, Old and New." The Bookman 33.3 (may 1911): 309-14. Kaplan, E. Ann. "Theories of Melodrama. A Feminist Perspective," Women and 
Performance 1.1 (1983):40-48.

Lichtblau, Myron I. The Argentine Novel in the Nineteenth Century. Nueva York: Hispanic Institute in the United States, 1959.

Mayo, Carlos. Porque la quiero tanto. Historia del amor en la sociedad rioplatense (1750-1860). Buenos Aires: Biblos, 2004.

Meyer, Marlyse. "Los modos de producción rocambolesca.” El folletín y sus destinos. Migraciones y trasposiciones en los imaginarios culturales argentinos del siglo XX. Ed. María Inés Laboranti. Trad. Estefanía Viglione. Santa Fe: Universidad Nacional del Litoral, 2012. 243-284.

Molina, Hebe. Como crecen los hongos: La novela argentina entre 1838 y 1872. Buenos Aires: Teseo, 2011.

---. "Novelas decimonónicas en el margen. Una revisión desde la poética histórica." Gramma 24.50 (2013): 28-48.

Pelliza de Sagasta, Josefina. Margarita. Buenos Aires: El Orden, 1875.

---. La chiriguana. Buenos Aires: Imprenta Santiago del Estero 176, 1877.

Ramos, Julio. Desencuentros de la modernidad en América latina. México: FCE, 1989.

Singer, Ben. Melodrama and Modernity. Ed. John Belton. New York: Columbia UP, 2001.

Sosa de Newton, Lily. Diccionario biográfico de mujeres argentinas. Buenos Aires: Plus Ultra, 1986.

Williams, Raymond. "Dominante, residual, emergente.” Marxismo y literatura. Trad. Pablo di Masso. Barcelona: Ediciones Península, 1980. 143-149.

Zanetti, Susana. La dorada garra de la lectura. Lectoras y lectores en América Latina. Rosario: 
Beatriz Viterbo Editora, 2010.

Zó, Ramiro Esteban. "Funciones de la novela sentimental hispanoamericana durante el siglo XIX.” Cuadernos del CILHA 8.9 (2007): 79-97. 